\title{
Article \\ Factors Influencing and Contributing to Perceived Safety of Passengers during Driverless Shuttle Rides
}

\author{
Claudia Luger-Bazinger ${ }^{1, * \mathbb{D}}$, Cornelia Zank1 ${ }^{1}$, Karin Klieber ${ }^{2}$, Veronika Hornung-Prähauser ${ }^{1}$ and $^{\text {Karl Rehrl }}{ }^{1} \mathbb{D}$ \\ 1 Salzburg Research Forschungsgesellschaft mbH, 5020 Salzburg, Austria; \\ cornelia.zankl@salzburgresearch.at (C.Z.); veronika.hornung@salzburgresearch.at (V.H.-P.); \\ karl.rehrl@salzburgresearch.at (K.R.) \\ 2 Department of Economics, University of Salzburg, 5020 Salzburg, Austria; karin.klieber@plus.ac.at \\ * Correspondence: claudia.luger-bazinger@salzburgresearch.at; Tel.: +43-662-2288-256
}

Citation: Luger-Bazinger, C.; Zankl, C.; Klieber, K.; Hornung-Prähauser, V.; Rehrl, K. Factors Influencing and Contributing to Perceived Safety of Passengers during Driverless Shuttle Rides. Future Transp. 2021, 1, 657-671. https://doi.org/10.3390/ futuretransp1030035

Academic Editor: Armando Cartenì

Received: 30 August 2021

Accepted: 25 October 2021

Published: 5 November 2021

Publisher's Note: MDPI stays neutral with regard to jurisdictional claims in published maps and institutional affiliations.

Copyright: (C) 2021 by the authors Licensee MDPI, Basel, Switzerland. This article is an open access article distributed under the terms and conditions of the Creative Commons Attribution (CC BY) license (https:/ / creativecommons.org/licenses/by/ $4.0 /)$.

\begin{abstract}
This study investigates the perceived safety of passengers while being on board of a driverless shuttle without a steward present. The aim of the study is to draw conclusions on factors that influence and contribute to perceived safety of passengers in driverless shuttles. For this, four different test rides were conducted, representing aspects that might challenge passengers' perceived safety once driverless shuttles become part of public transport: passengers had to ride the shuttle on their own (without a steward present), had to interact with another passenger, and had to react to two different unexpected technical difficulties. Passengers were then asked what had influenced their perceived safety and what would contribute to it. Results show that perceived safety of passengers was high across all different test rides. The most important factors influencing the perceived safety of passengers were the shuttle's driving style and passengers' trust in the technology. The driving style was increasingly less important as the passengers gained experience with the driverless shuttle. Readily available contact with someone in a control room would significantly contribute to an increase in perceived safety while riding a driverless shuttle. For researchers, as well as technicians in the field of autonomous driving, our findings could inform the design and set-up of driverless shuttles in order to increase perceived safety; for example, how to signal passengers that there is always the possibility of contact to someone in a control room. Reacting to these concerns and challenges will further help to foster acceptance of AVs in society. Future research should explore our findings in an even more natural setting, e.g., a controlled mixed traffic environment.
\end{abstract}

Keywords: perceived safety; autonomous shuttles; autonomous driving; driverless shuttle

\section{Introduction}

In recent years, a substantial and fast-growing number of research institutes devoted their attention to autonomous driving. Even though the effort invested and the progress made in technological terms were substantial [1], autonomous vehicles (AVs), and especially shuttles and busses with minimal involvement of a driver or driverless shuttles (SAE Level 4 and 5 [2]), will only prevail in our transport system if society accepts and uses these services [3-5]. The long-term vision is to implement a system of autonomous shuttles that run in a mixed traffic environment and enjoy high acceptance. However, people's acceptance and willingness to use AVs depends on several factors. Research has shown that sociodemographic characteristics - such as age [6,7], gender [8,9], income and educational level $[6,10]$-affect the acceptance of AVs as a common means of transport. Similarly, contextual factors such as purchase prices, incentives [11], level of familiarity [12], and travel and waiting times [13] have an impact on the willingness to use autonomous shuttles. One of the most important aspects for acceptance, however, is the perceived safety regarding AVs [5,14-19]. As Level 4 and especially Level 5 AVs would be a new form of transport with the lack of a human driver, users need to trust and feel secure in driverless shuttles as a necessary prerequisite of acceptance (as research on the acceptance 
of automated systems has shown [20]). Therefore, perceived safety will play a central role for the wide adoption of AVs in the future.

We explored perceived safety of passengers in an autonomous shuttle (SAE Level 4), without a steward on board, over four test rides representing possible real-world situations that could occur once AVs are part of a public transport system. While many studies investigate people's perceived safety in relation to AVs, few do so with passengers that have experienced a ride in an AV [21-23], even though a physical experience of a shuttle ride might be important to overcome flawed expectations and misconceptions [24]. Therefore, some studies $[4,25-28]$ started to assess passengers' attitudes and experiences with AVs after giving them the opportunity to experience driverless vehicles. However, the ride in the $\mathrm{AV}$ was either conducted with a steward [4] or with a Wizard of Oz setup (i.e., a human driver was operating the vehicle in a concealed manner [26]). To our knowledge, no experiences of passengers in autonomous shuttles without a steward on board have been explored. We seek to expand on the existing knowledge about perceived safety of autonomous shuttles with passengers who physically experienced autonomous driving without a (concealed) steward on board. The aim is to draw conclusions on heightening people's perceived safety in driverless shuttles by an explorative analysis.

\subsection{Perceived Safety in AVs}

$\mathrm{AVs}$ are designed for an enjoyable and convenient experience by reducing unnecessary human inputs, efforts, and errors [29]. However, this missing human involvement may also threaten perceived safety. Indeed, studies show that many people are doubtful about the reliability and safety aspects of AVs [16,30]. Autonomous shuttles of SAE Level 4 or 5 without the necessary involvement of a driver or steward can challenge perceived safety as: (1) passengers are confronted with a new technology they might be doubtful about; and (2) in usual public transport settings, people are used to having a driver as someone who can be approached for general information or can intervene in case of unexpected or unpleasant events occurring during the ride [31]. Previous research [32,33] already indicates that passengers' perceived safety in driverless shuttles is challenged due to the fact that there is no driver present (a similar finding comes from user acceptance on lack of staff on automated trains [34]). This is critical as perceived safety is an important factor for the acceptance and the frequency and willingness to use AVs: If people feel safe, they would also be willing to use AVs and therefore, perceived safety is discussed as one of the major barriers to AV adoption [23]. Previous studies found that people think AVs should offer a much higher level of safety than vehicles operated by humans [35,36], but that people's perceived safety is reduced with an increase in autonomy of vehicles [37]. People in both Western and Eastern parts of the world [33,38] seem to be doubtful about technical aspects of AVS (e.g., cyber security) as well as about the safety of passengers and pedestrians [39].

People feel safe when their perception of danger decreases while their perception of comfort increases when interacting with technology [40]. Although the objective safety in AVs can be increased by technological advances, the perceived safety of AVs also plays a critical role in adoption and use of AVs [41]. The latter depends on many different factors, some posing challenges for technicians and engineers or being beyond their control. Salonen [33] discusses subjective traffic safety and in-vehicle security with regard to driverless shuttles, with subjective traffic safety relating to fear of accidents and in-vehicle security relating to fear of crimes. These aspects are relevant to a real-world application of autonomous shuttles as part of public transport and to the feeling of perceived safety of passengers that we build on for this study.

Research has identified a number of factors that influence people's perceived safety or trust when interacting with autonomous vehicles: for example, Choi and Ji [42] proposed three dimensions for trust in an autonomous vehicle: (1) system transparency (the belief that the system is predictable and understandable), (2) technical competence (the belief that the system performs tasks accurately), and (3) situation management (the belief that the user 
can regain control over the situation if needed). Relating to these dimensions, Ekman and colleagues [26] found that a defensive driving style of the $\mathrm{AV}$ that is more predictable leads to greater trust in users (as an example for technical competence). Providing information about the system in AVs has also been discussed as one factor for building trust, but there can also be too much information, leading to greater anxiety of AV users [43]. Trust can be certainly regarded as a psychological construct similar to perceived safety, however, they are distinct concepts [44]. For example, when using an autonomous shuttle, perceived safety means that one is sure that no physical or psychological harm would ensue, whereas trust includes relying on the autonomous shuttle to get to places on time and to stop at desired destinations (i.e., being vulnerable to transport with the AV). In its similarity to perceived safety, trust can certainly help with informing situations and factors that challenge perceived safety in AVs.

\subsection{Study Design}

We sought to investigate perceived safety of passengers in an autonomous shuttle, especially in situations where perceived safety could be challenged. We designed situations that could possibly occur in a future where Level 4 and 5 autonomous shuttles are part of public transport, and let passengers experience these simulated situations in test rides. The test rides were designed based on the following aspects:

1. A Level 4 and especially Level $5 \mathrm{AV}$ would not need a human driver or steward, and a passenger could potentially be alone in an autonomous shuttle, which can influence perceived safety [31]. Passengers would need to trust the technology of the automated system and would have no way to speak to a human driver or steward directly.

2. Building on findings from public transport, being alone with unknown people is one of the greatest sources of anxiety [45]. People are especially concerned about safety inside an autonomous shuttle [32], as they worried of being harassed or threatened when there is no driver or steward to potentially intervene [46]. This characteristic of the lack of a human driver or steward is a potential challenge for perceived safety, therefore, we designed a test ride with a person who behaves obnoxious and is not pleasant to share a ride with.

3. If automated systems are not working properly, people are hesitant to use them [20]. In case of situations of technical problems in an autonomous shuttle, passengers would need to trust technology for a safe continuation of the journey or a resolution of the problem. Technical limitations and difficulties are challenging for perceived safety, especially with AVs as a new technology, as people are skeptical about the reliability and technical aspects of AVs already [16]. With the autonomous shuttle we used, we identified two situations where technical difficulties might be happening in future use.

For our study, we designed four different test rides for passengers with an autonomous shuttle on a test area. Our goal was to relate to and expand findings from previous research. For example, driving style of the AV [26] and trust in technology [47] have been discussed to be important for perceived safety. However, as we were simulating possible situations that might occur when autonomous shuttles are a part of public transport and perceived safety might be challenged (e.g., being in an AV without a steward), we can provide new insights into passengers' experience. Choi and Ji [42] provide dimensions of trust that help structure passengers reactions in questionnaires.

\section{Materials and Methods}

\subsection{Shuttle and Test Area}

The Austrian regulation for automated driving stipulates that a steward must be on board during test drives with driverless vehicles on public roads. In order to gain first experiences with passengers who physically experienced autonomous driving without a steward on board, the test rides were performed on a closed-off, confined area. There were no other vehicles or road users in the area. 
The test rides with the automated shuttle were conducted in September 2019 on a closed proving ground near Salzburg, Austria, with an EZ10 Generation 2 shuttle from the French supplier EasyMile, which is classified under restricted ODD as a SAE Level 4 automated shuttle (see Figure 1). For the test rides, a shuttle track with three bus stops (indicated with bus stop signs) has been set up. The shuttle track was $150 \mathrm{~m}$ long (one direction), and the ride itself lasted about $90 \mathrm{~s}$. A control room for supervision to ensure safety was situated closely to the test track, but precluded direct eye contact with the proving ground and the shuttle so participants could not see it. The control room supervised the following aspects: status of the vehicle (position, speed, door open/closed), mission (i.e., the current trip of the shuttle), warnings, and error messages. If required, video (inside the shuttle, front and rear view) and audio (inside only) signals could be activated. Furthermore, the supervisor in the control room could stop and start the shuttle. In addition, a container was set-up near the track for better localization for the shuttle. While participants were not informed about details, they were instructed that the shuttle was equipped with a visual and audio connection to the control room, that an emergency button was available for an abrupt, immediate stop, and that the rides would be supervised.

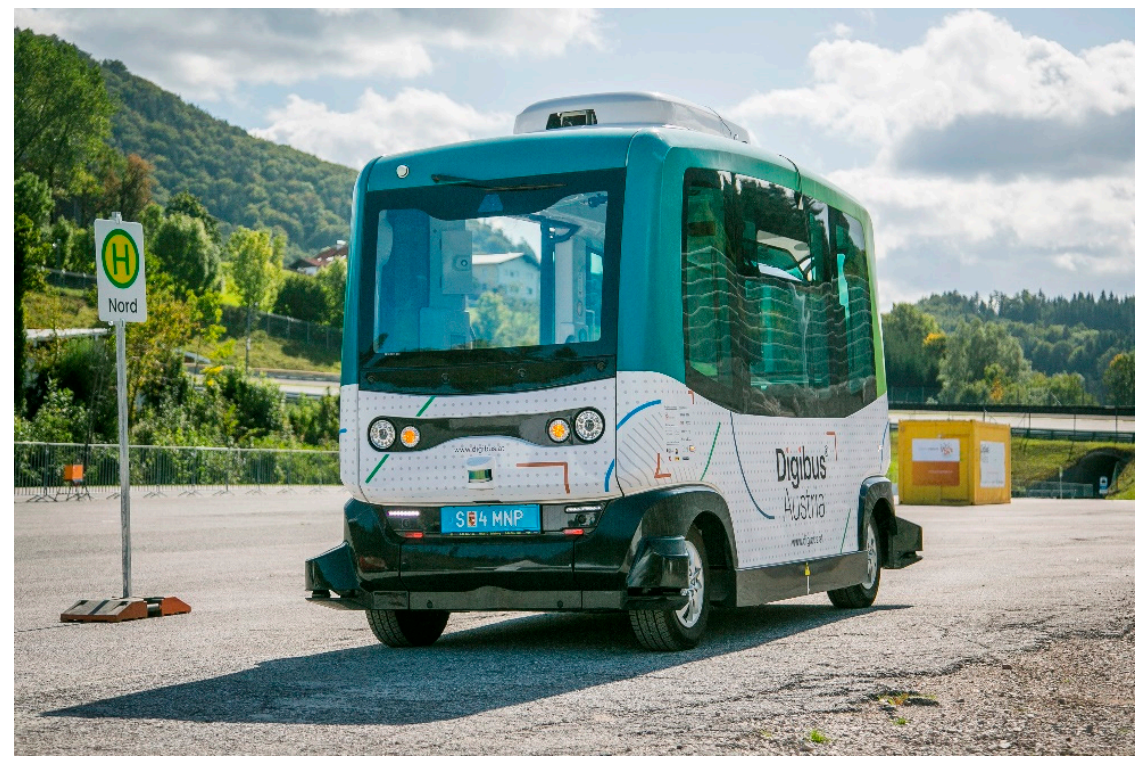

Figure 1. The automated shuttle at a bus stop during test rides (picture copyright: Salzburg Research/wildbild/Rohrer).

\subsection{Recruitment and Instruction of Passengers}

Passengers were recruited via local newspapers and postings on the research project website, stating that this would be a driverless shuttle on a closed-off area. Sixteen passengers were available for day of the study, which lasted about $3 \mathrm{~h}$, including instruction, test rides, breaks, and debriefing.

Once arriving at the test area, passengers were instructed about the purpose of the study, experience of a driverless shuttle. Passengers were told that there would be multiple test rides. In addition, passengers were made familiar with the shuttle, received relevant safety instructions (e.g., all passengers needed to be seated during the ride) and were made aware of the emergency button. After the instruction, passengers gave their written agreement to be part of the scientific study.

Each passenger went through all the test rides. The test rides were conducted in the mentioned order (see below) due to waiting times and administrative issues. Passengers who already experienced a certain test ride waited separately from the others in order to minimize exchange. As each of the passengers was asked to ride the shuttle alone, and each subgroup of passengers had to complete the additional three test rides, the sample 
of passengers was kept small in order to avoid waiting times that could have affected passengers.

\subsection{Description of Test Rides}

Four different test rides were conducted (see Section 1.2.), representing aspects challenging perceived safety as described above. As technical difficulties can relate to technical problems, as well as to technical restrictions that disrupts the journey, both aspects were included.

- $\quad$ Test ride 1 (riding as single passenger): The task for the passenger was to ride the autonomous shuttle alone (no steward or driver present). The instruction to the passenger was to ride the driverless shuttle on his or her own from a starting point to a predefined stop.

- $\quad$ Test ride 2 (interacting with another passenger): The aim of the second test ride was to explore perceived safety with other passengers on board. The instruction was to ride from a starting point to a predefined stop. This time, an actor (member of the research team), posing as an annoying passenger entered the shuttle. As soon as the shuttle departed, the actor started to behave in an unpleasant manner. He listened to loud music, situated himself closely to the passenger and gesticulated wildly in order to provoke a small-to-modest inconvenience.

- $\quad$ Test ride 3 (capacity management/technical difficulties): Test ride 3 dealt with capacity limits of the shuttle. Several passengers, exceeding the number of permitted passengers (six), were given the task to ride from a starting point to a predefined stop or to get on an already full shuttle. Passengers had the option of either entering the shuttle regardless of the overcrowded conditions or waiting until the shuttle returned.

- $\quad$ Test ride 4 (emergency/technical difficulties): The aim of this test ride was to learn about passengers' perceived safety in case of a sudden, unexpected stop during the test ride between two stops. Six passengers at a time were asked to ride from a starting point to a predefined stop. The shuttle stopped during this journey abruptly and unexpectedly. After $60 \mathrm{~s}$, an announcement was made indicating the detection of a technical problem and the continuation of the ride after correction of the defect. If the passengers contacted the control room before the expiration of the $60 \mathrm{~s}$, no announcement was made. If the passengers did not show any reaction $120 \mathrm{~s}$ after the announcement in form of contacting the control room or leaving the shuttle, the announcement was repeated every $30 \mathrm{~s}$. After approximately $6 \mathrm{~min}$, the shuttle continued its ride and drove the remaining passengers to the predefined stop.

\subsection{Questionnaires and Coding of Answers}

After each test ride, passengers filled out a questionnaire either on a provided tablet or their smartphone (questionnaire was administered via LimeSurvey). In order to remain the explorative character of the study in this new setting for passengers, we mainly worked with open-ended questions while investigating passengers' perceived safety. Answers to open-ended questions can be a valuable tool in helping researchers for developing questionnaires or for not missing information that passengers might provide-however, it is important to use and analyze answers to open-ended questions strategically [48]. We follow these recommendations and use open-ended questions for not limiting passengers' chance to report their experiences. Research findings on factors that influence perceived safety inform the way we coded passengers' answers: They helped to decide on categories that we established in order to code the answers for quantitative analyses, at the same time, passengers were able to be more flexible in their responses than when providing closed-format questions only. Passengers were asked about factors that influenced their perceived safety as well about what would increase their perceived safety with open-ended questions, where passengers were given the option to provide multiple answers. For analyzing the open-ended questions, we followed a recommended procedure in order to produce codes suitable for quantitative analysis $[48,49]$. Open-ended questions in the 
questionnaire were coded only after investigating all answers. Categories for coding were derived partly from literature review (i.e., common factors that influence perceived safety) and partly from given answers in the questionnaire. This ensured the categorization of all given answers without producing too many different categories. Answers were grouped into four categories in the case of factors that influence perceived safety and to five distinct categories for factors that would increase perceived safety. The results are reported in the following section.

\section{Results}

In our explorative study, 16 passengers ( 3 female, 13 male) participated in the driverless test rides (all passengers experienced all rides) (see questionnaire in Appendix A). Age groups ranged from 21-70 years old with $\mathrm{n} 1=2$ (21-30 years), $\mathrm{n} 2=2$ (31-40 years), $\mathrm{n} 3=3$ (51-60 years), $\mathrm{n} 4=6$ (61-70 years), and $\mathrm{n} 5=3$ (>70 years). When passengers were asked whether they had any knowledge about AVs, eight passengers stated that they were familiar to some degree with AVs, five stated that they had basic or even more detailed knowledge about AVs, and three stated that they were not familiar with AVs.

In general, the perceived safety of the passengers in the study was high. Passengers were asked after each test ride how safe they have felt overall, and they felt "safe" (27\% of answers) or "very safe" (73\% of answers). None of the passengers chose the option "less safe" or "not safe" on the Likert scale after any test ride.

After having experienced all four test rides, passengers were asked for their desire to contact a person in a control room in various situations (see Figure 2 for percentages). For general information about the route, schedule, or connections on route only five passengers would desire information from a person in a control room. Contrary, in case of an unexpected stop of the vehicle, all passengers would like to contact a person in a control room. Similarly, 11 passengers want to interact with a person in a control room in emergency situations or when feeling harassed from other passengers. We collapsed the situations into emergency (relating to unexpected stops, harassment, emergency) and nonemergency situations (relating to information requests). A chi-square test of independence showed that passengers prefer to contact a person in a control room to a significantly higher extent in emergency than in non-emergency situations $X^{2}(1, \mathrm{~N}=15)=6.7, p=0.009$.

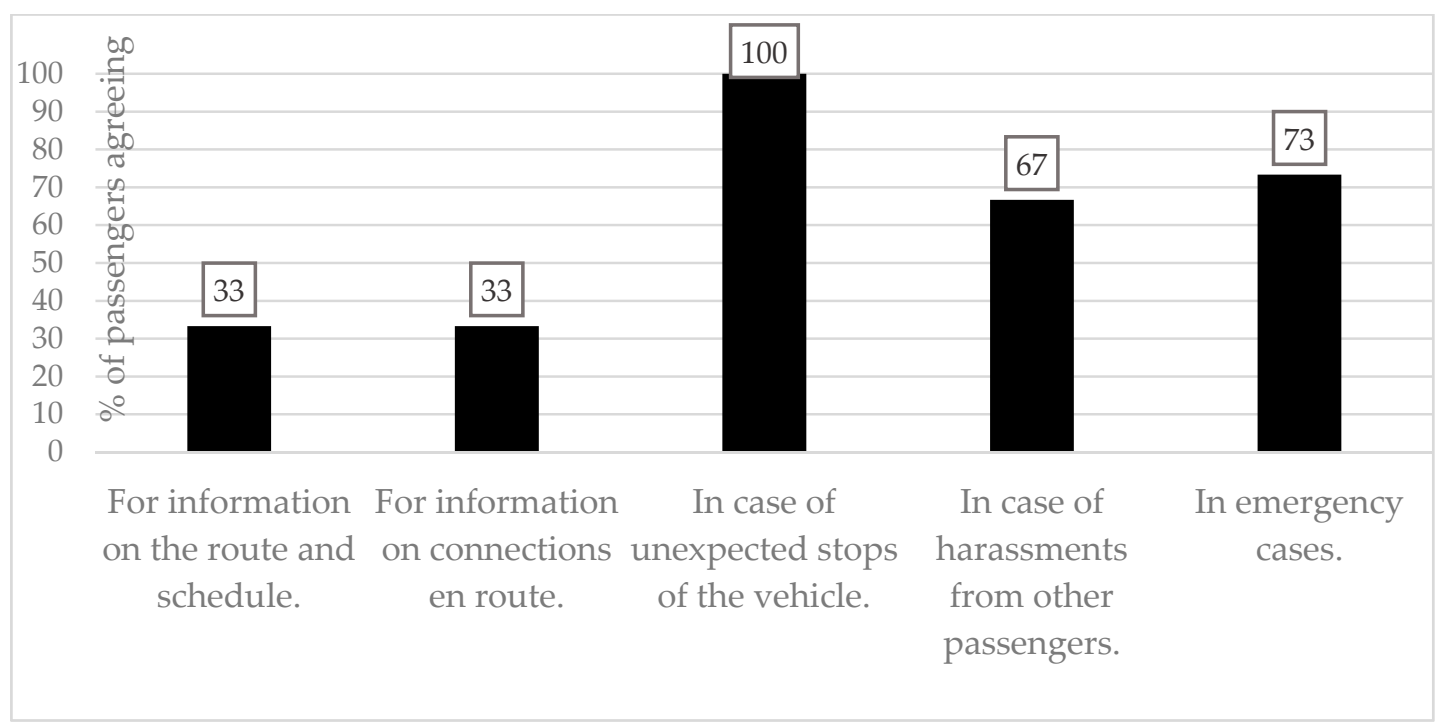

Figure 2. Situations in which passengers would like to contact a person in the control room ("In which situations would you use an audio or a video connection to someone in a control room?").

At the end of test rides, passengers were asked what factors would influence their perception of road safety of the autonomous shuttle in a future where that shuttle was 
already operating with normal traffic (similarly to [14]). Eleven (73\%) passengers stated that it would not matter their perception of safety of the shuttle if the autonomous shuttle drove on a separate lane in traffic, nine $(60 \%)$ passengers stated it would not be important that the shuttle behaves like a vehicle with a driver.

\subsection{Factors That Influenced Perceived Safety}

When asked about which factors influenced their perceived safety, across all test rides, passengers made 63 statements that were further analyzed. Passengers' answers could be categorized into four different categories (driving style of the shuttle, trust in technology, equipment, and presence of unpleasant passenger). A chi-square test of goodness of fit over all four test rides showed a significant difference whether categories were mentioned equally often in passengers' statements $X^{2}(3, N=63)=13, p=0.004$. As recommended by [50], residuals show that the unpleasant passenger was mentioned the least over all test rides, followed by driving style and trust in technology being mentioned significantly more often.

Illustrated in Figure 3, passengers' statements show that the driving style of the shuttle plays a key role, named in 35\% of all answers. One of the passengers, for example, felt safe due to a "ride without jerking $[\ldots]$ ". Another passenger appreciated "the very smooth ride" and yet another passenger enjoyed the "[ ... ] smooth braking and the very low driving sounds". Equally important, in 33\% of the statements, people indicate that their own trust in technology influences their perceived safety. One passenger listed the following factors: "trust in technology, feeling strange due to novelty, basic trust needs to be present". Another passenger stated that he or she "has trust in the new technology" leading to a solid level of perceived safety, some passengers mentioned that they have "trust in the control room". Moreover, passengers named the equipment of the driverless shuttle as an influencing factor in $25 \%$ of the given answers. One passenger explained a high perceived safety by having "a lot of space [ ... ]". Another one enjoyed the "overview of the ride, big windows $[\ldots]$ ". Another passenger stated that the "[ $\ldots$ ] equipment of the shuttle" contributed to his or her perceived safety. Less than $10 \%$ of all answers concerned the presence of an unpleasant passenger. These answers stem mainly from test ride 2 , in which people faced an unpleasant passenger.

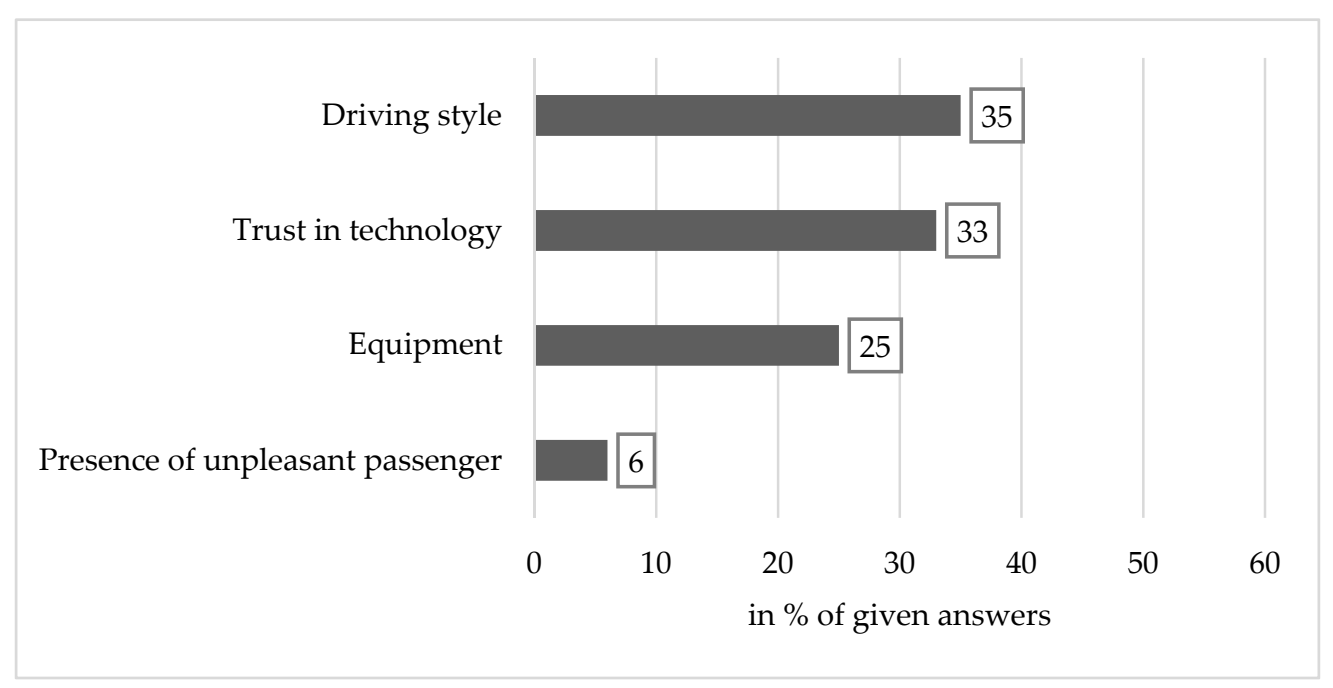

Figure 3. Factors influencing perceived safety ("What has influenced your feeling of safety?").

As passengers gained experience with the autonomous shuttle over the four test rides, we checked whether the influence of the shuttle's driving style decreased with repeated use of the shuttle. A chi-square test of independence showed that driving style, compared to the other categories mentioned for influencing perceived safety, differed significantly in 
the four test rides $X^{2}(3, N=63)=11.35, p=0.009$ (see also Figure 4 for test rides). Residuals showed that driving style was mentioned more than other categories in test ride 1 , and less frequently than others in test ride 3 and 4 . As two test rides dealt with unexpected challenges regarding the technology of the shuttle, we tested whether mentioning trust in technology in the statements differed over the four test rides, but lead to no significant effect $X^{2}(3, N=63)=0.52, p=0.913$. Therefore, mentioning trust in technology happened equally often in all four test rides.

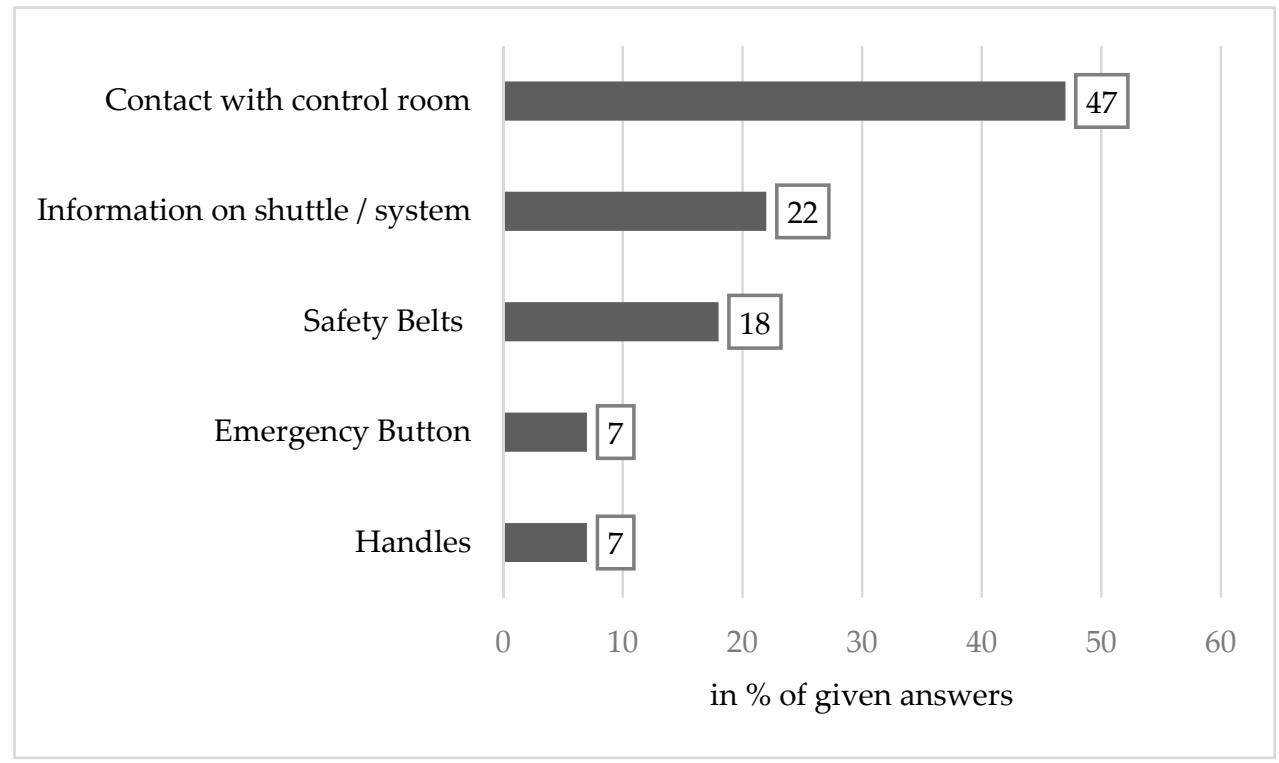

Figure 4. Suggestions for increasing perceived safety ("What would contribute to your feeling of safety?").

\subsection{Suggestions for Increasing Perceived Safety}

After each test ride, passengers were asked what would contribute to an increase of perceived safety. In total, we collected 45 statements and categorized passengers' answers into five different categories (contact with control room, information on shuttle/system, safety belts, emergency buttons, handles). With a chi-square goodness of fit test over all four test rides, we explored whether there was a difference in how often a category was mentioned, which showed a significant result $X^{2}(4, N=45)=24.22, p<0.001$. Residuals show that the contact with someone in a control room was mentioned the most, and that emergency button and handles were mentioned less frequently than the other categories. As it would be likely that, especially in emergency situations, people would like to have information or contact someone in a control room, we looked at whether these factors differed in the four test rides. Neither information on the shuttle/system $\left(X^{2}(3, N=45)=2\right.$, $p=0.572)$ nor contact with control room $\left.X^{2}(3, N=45)=2.8, p=0.421\right)$ was mentioned more frequently in one of the four test rides.

As can be seen in Figure 4, almost 50\% of all answers concerned the possible contact with someone in a control room, either active or passive. For example, one passenger stated that the perceived safety could be increased by an "understandable voice communication without interruptions". Similarly, two other passengers think that a "better quality of announcements" and a "better and faster connection to the control room [... ]" would contribute positively to the perceived safety. One passenger even would wish for the "total attendance [of a steward]".

Nearly a quarter (22\%) of the statements made by passengers showed that an adequate amount of information about the autonomous shuttle and the underlying system would contribute to their perceived safety ("more information about the system would reduce 
skepticism before boarding"). Additionally, people mentioned a few equipping factorssuch as safety belts, emergency buttons, and handles or other holding devices.

\subsection{Results of Test Rides}

We split up the answers according to the different test rides. The answers given in test ride 1 are presented in the upper panel of Figure 5. Most answers were concerned with the driving style of the shuttle as influence on perceived safety. Regarding suggestions for an increase in perceived safety, passengers included safety belts in over $40 \%$ of their answers, followed by the available contact with someone in the control room.

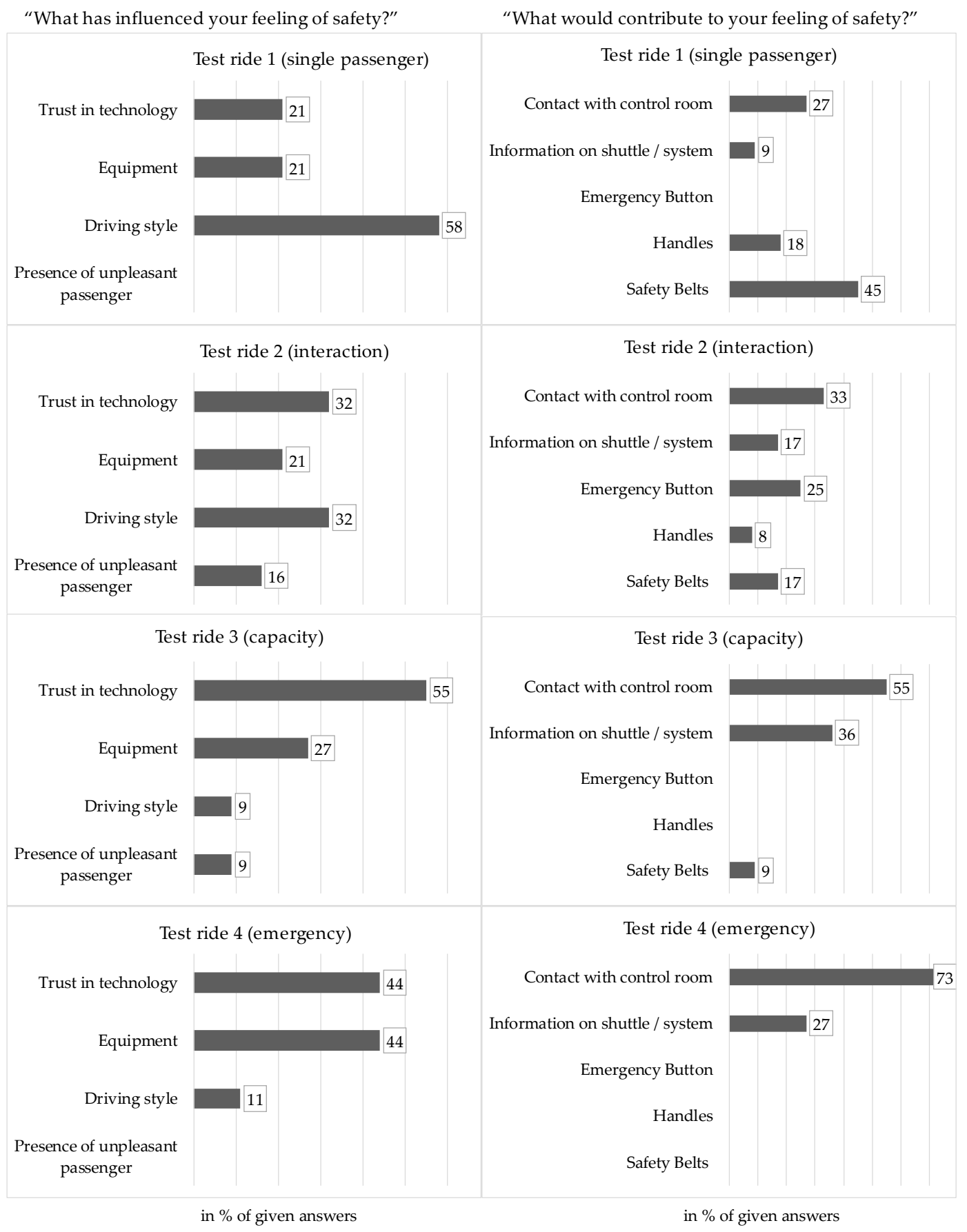

Figure 5. Results per test ride (\% of given answers). Left panel shows responses to the question: "What has influenced your feeling of safety?", right panel shows responses to the question: "What would contribute to your feeling of safety?". 
In test ride $2,32 \%$ of answers dealt with the passengers' trust in technology and the driving style. Even though this test ride was constructed to create an unpleasant situation, only $16 \%$ of the answers indicated a lower perceived safety due to the unpleasant passenger. For contributions to increase perceived safety, the availability of contacting someone in a control room was named in 33\% of the statements and emergency buttons in $25 \%$.

The results of test ride 3 show that people indicated the factor trust in technology influencing their perceived safety in 55\% of their statements. For an increase in perceived safety, passengers named potential contact with someone in a control room in $55 \%$ of all given answers. Similarly, in the emergency management test ride, passengers included the factor of trust in technology and the equipment of the shuttle in over $40 \%$ of their given answers, followed by the driving style. In $73 \%$ of the answers, we found statements about the importance of contact with someone in a control room.

\section{Discussion}

In order for people to adopt traveling in $\mathrm{AVs}$, $\mathrm{AVs}$ need to not only be objectively safe, but to also instill a feeling of safety in people [5,14-17]. Our study provides an insight on what affects people's perceived safety and what they value for increasing their perceived safety in autonomous shuttles as future part of public transport. Sixteen passengers experienced a driverless shuttle ride without a steward or research member on board and reported their perceived safety over four different test rides, representing situations that are relevant to the use of driverless shuttles that might affect passengers' perceived safety.

In general, passengers felt safe across all test rides. This relates to research on what changes opinions about AVs: Although the public opinion about AVs might be skeptical, with safety concerns for passengers as well as for pedestrians being the biggest skepticisms [30,37,39,51,52], people's opinions and attitudes positively change when they experience a ride in an $\mathrm{AV}[22,53]$, and perceived safety increases with experience with a driverless shuttle [54], people would be also more willing to pay for a ride in a shuttle ride after having experienced it [55]. In our study, passengers indicated after their experience with the autonomous shuttle that their perception of road safety would not need the shuttle to have a separated lane when they thought about a future where autonomous shuttles are already part of normal traffic. The former result is in line with Howard and Dai's finding [14] on the perception of the operation of self-driving cars. In addition, passengers in the present study indicated that the shuttle would not need the same driving style as a human driver.

Regarding factors that influenced passengers' perceived safety, the driving style of the shuttle as well as passengers' trust in the technology were repeatedly mentioned. Across the four different test rides, passengers mentioned the driving style of the shuttle less frequently, as they gained experiences with it. Previous research shows that driving style has been also shown to be an important factor for acceptance of AVs in the older population [56]. Regarding factors that would increase their perceived safety, the option to contact someone in a control room was mentioned most often. Passengers also indicated that in case of an emergency, they would want to have the option of contacting a control room more often than during another, non-emergency situation they might face.

Our results show that passengers seem to mention aspects of all three dimensions of Choi and Ji's [42] for trusting AVs. Passengers related especially to situation management and system transparency-passengers want to be able to control situational factors (e.g., emergencies) by getting help from a control room or steward; and passengers want to have information about the system of the driverless shuttle, relating to previous research on the need to know about the system of AVs [43]. Relating to the dimension of situation management, passengers mentioned significantly more often that the option for contacting someone in a control room would increase their perceived safety. Similar to the findings of Ekman and colleagues [26], our results also support that passengers favor a predictable, calm driving style of the shuttle. This aspect lost importance after passengers gained 
experience with the autonomous shuttle in our study. Driving style can be seen as a facet of the technical competence of the AV [42].

In addition to these three dimensions, passengers mentioned that trust in technology influences their perceived safety in the driverless shuttle, some of them referring to an inherent trust in new technology. This relates to results that trust in the technology of an $\mathrm{AV}$ is an important predictor of comfort while riding [47], and similarly, that technology acceptance predicts whether people would be willing to use a self-driving shuttle [57]. Some of the passengers in the current study mentioned that they trust the decisions of the control room, another frequently mentioned factor to increase perceived safety was the possibility to contact someone in the control room. This result is in line with previous research on supervision and operation of AVs, showing that many people prefer supervision by a human driver in an AV [58]. Similarly, Nordhoff and colleagues [45] found in qualitative interviews that parts of passengers prefer remote supervision or the presence of a steward on board of the AV, and König and Neumayr [59] found that people do not like the idea of giving up control in an automated car. Howard and Dai [14] found that people dislike the idea of losing control in an $\mathrm{AV}$, this relates to the need to be able to contact someone in charge in our study.

For further research and design of AVs, this has implications on how best to fulfill the need of people to have contact with a control room (and holds interesting research questions, e.g., whether human or robotic interaction with or without anthropomorphous features would affect perceived safety $[41,60])$. In addition, it might be necessary to effectively communicate the option to contact a control room and to give information about the technology of $\mathrm{AVs}$ in order to make passengers feel safer.

\section{Limitations of the Study}

Due to the limited group size of 16 passengers, the sample of passengers contained with few women and few young people in the group. While we tried to investigate perceived safety over various test rides, some passengers were probably aware that certain aspects were staged in the test rides (e.g., one passenger made a remark on the questionnaire that the annoying person in test ride 2 was an actor). In future research, efforts should be made to make these test rides as real and natural as possible.

Another limitation of the study is a self-selection bias. While some participants of the study had very limited knowledge about automated driving, it can be assumed that passengers still had some interest in this technology. Conducting this study in a more open and representative setting would be interesting for future research.

While this was a driverless shuttle ride, it was still conducted on a proving ground without any real traffic nearby, as legal regulations do currently not allow a driverless shuttle on public roads without a steward on board. However, this would be of course a much more realistic setting, as there is not only more traffic around it, but situations are dynamic with a number of different road users, and additional people, objects, and even animals. It will be interesting to see how and whether the findings will change in more real world situations as soon as the legal regulations will allow it. Although this was a setting without other road users in a closed-off area, we made sure to make the setting as realistic as possible- - e.g., we used signs for the shuttle stops, and left participants among themselves to experience the test rides. In addition, participants were informed that the shuttle was already in use in a nearby town (within the Digibus ${ }^{\circledR}$ Austria project, although a steward had to be present in that case since the test rides were conducted on a public road). Therefore, we made sure to adhere to a realistic setting as much as possible to ensure the validity of our results.

\section{Conclusions}

- The main conclusions of our explorative study are that driving style of the shuttle and trust in technology were significant factors that influenced passengers' perceived safety. 
- Readily available contact with someone in a control room would significantly contribute to an increase in perceived safety while riding a driverless shuttle.

- While driving style was important, it was mentioned less as passengers got experienced in use with the shuttle.

- For researchers as well as technicians in the field of autonomous driving, our findings could influence the design and set-up of driverless shuttles in order to increase perceived safety, for example, how to signal passengers that there is always contact to someone in a control room possible who is assisting (not only) in the case of an emergency, or to explore the best way to instill trust in the technology of AVs in passengers. With attention to concerns of potential passengers and more experience of passengers in shuttles, this will help to foster acceptance of AVs in society.

- Future research should explore our findings in an even more natural setting, e.g., a controlled mixed traffic environment with dynamic traffic situations.

Author Contributions: Conceptualization, C.L.-B., C.Z. and K.K.; Methodology, C.Z., V.H.-P. and K.R.; Formal Analysis, C.L.-B. and K.K.; Writing-original draft preparation, C.L.-B., K.K. and C.Z.; Writing-review and editing, C.L.-B., V.H.-P., K.R. and C.Z.; Visualization, C.L.-B.; Supervision, K.R. and V.H.-P.; Project Administration, C.Z. and K.R.; Funding Acquisition, K.R. All authors have read and agreed to the published version of the manuscript.

Funding: The flagship project Digibus ${ }^{\circledR}$ Austria received funding from the Austrian Federal Ministry of Climate Action, Environment, Energy, Mobility, Innovation, and Technology as part of the "Mobility of the Future" program. The Austrian Research Promotion Agency (FFG) has been authorized for the program management (FFG grant number 865110). The lease of the EZ10 Generation 2 shuttle was financed by the Federal State of Salzburg.

Institutional Review Board Statement: Ethical review and approval were waived for this study, due to test rides being supervised at all times, and participants were informed about this during the instruction. The setting was not in any way harmful to participants, an ethics committee was not involved. All guidelines for ethics and data protection as required by national law as well the recommendations of the European commission were followed. Participants' right to privacy was protected, no personal data was collected, in order to adhere to the to the ethics and data protection recommendation by the European commission figure (https:/ / www.ffg.at/sites/default/ files/downloads/h2020_hi_ethics-data-protection_en.pdf) (accessed on 4 November 2021).

Informed Consent Statement: Informed, written consent about participation was obtained from all participants involved in the study.

Data Availability Statement: The complete dataset used and analyzed during the current study is available from the corresponding author on reasonable request due to protection of privacy of participants.

Conflicts of Interest: The authors declare no conflict of interest. The funding authority had no role in the design of the study; in the collection, analyses, or interpretation of data; in the writing of the manuscript, or in the decision to publish the results.

\section{Appendix A}

Questionnaire used (translated from German):

Before the test rides started:

- Your age:

- Your gender:

- Do you have any knowledge about automated vehicles? (single choice format)

Yes, I have in-depth knowledge about it.

Yes, I have a basic understanding.

Yes, I have heard about it.

No

After each test ride: 
- How save did you feel during the ride? (single choice format)

$\begin{array}{ll}\bigcirc & \text { Very safe } \\ \bigcirc & \text { Safe } \\ \bigcirc & \text { Less safe } \\ \bigcirc & \text { Not safe }\end{array}$

- Which factors had an effect on your feeling of safety? (open-ended question)

- What could increase your feeling of safety? (open-ended question)

After all test rides were finished:

- In which situations would you use an audio or a video connection to someone in a control room?

For information on the route and schedule. (yes/no)

For information on connections en route. (yes/no)

In case of unexpected stops of the vehicle. (yes/no)

In case of harassments from other passengers. (yes/no)

In emergency cases. (yes/no)

- What factors would you consider necessary for the automated shuttle to be safe in future traffic?

$\bigcirc \quad$ The automated shuttle drives in its own lane without other road users around. (yes/no)

$\bigcirc$ The automated shuttle behaves just like a shuttle with a human driver. (yes/no)

\section{References}

1. Wang, Z.; Bian, Y.; Shladover, S.E.; Wu, G.; Li, S.E.; Barth, M.J. A Survey on Cooperative Longitudinal Motion Control of Multiple Connected and Automated Vehicles. IEEE Intell. Transp. Syst. Mag. 2020, 12, 4-24. [CrossRef]

2. SAE Taxonomy and Definitions for Terms Related to Driving Automation Systems for On-Road Motor Vehicles-SAE International. Available online: https://www.sae.org/standards/content/j3016_202104/ (accessed on 27 October 2021).

3. Mitteregger, M.; Bruck, E.M.; Soteropoulos, A.; Stickler, A.; Berger, M.; Dangschat, J.S.; Scheuvens, R.; Banerjee, I. AVENUE 21. Automatisierter und Vernetzter Verkehr; Daimler und Benz Stiftung; Springer: Berlin/Heidelberg, Germany, 2020.

4. Nordhoff, S.; de Winter, J.; Madigan, R.; Merat, N.; van Arem, B.; Happee, R. User acceptance of automated shuttles in Berlin-Schöneberg: A questionnaire study. Transp. Res. Part F Traffic Psychol. Behav. 2018, 58, 843-854. [CrossRef]

5. Stegmüller, S.; Werner, M.; Kern, M. Akzeptanzstudie "Robocab". Autonome Mobilitätskonzepte aus Sicht der Nutzer; Fraunhofer IAO: Stuttgart, Germany, 2019.

6. Haboucha, C.J.; Ishaq, R.; Shiftan, Y. User preferences regarding autonomous vehicles. Transp. Res. Part C Emerg. Technol. 2017, 78, 37-49. [CrossRef]

7. Payre, W.; Cestac, J.; Delhomme, P. Intention to use a fully automated car: Attitudes and a priori acceptability. Transp. Res. Part F Traffic Psychol. Behav. 2014, 27, 252-263. [CrossRef]

8. Hohenberger, C.; Spörrle, M.; Welpe, I.M. How and why do men and women differ in their willingness to use automated cars? The influence of emotions across different age groups. Transp. Res. Part A Policy Pract. 2016, 94, 374-385. [CrossRef]

9. Rice, S.; Winter, S.R. Do gender and age affect willingness to ride in driverless vehicles: If so, then why? Technol. Soc. 2019, 58, 101-145. [CrossRef]

10. Fraedrich, E.; Beiker, S.; Lenz, B. Transition pathways to fully automated driving and its implications for the sociotechnical system of automobility. Eur. J. Future Res. 2015, 3, 11. [CrossRef]

11. Shabanpour, R.; Golshani, N.; Shamshiripour, A.; Mohammadian, A. (Kouros) Eliciting preferences for adoption of fully automated vehicles using best-worst analysis. Transp. Res. Part C Emerg. Technol. 2018, 93, 463-478. [CrossRef]

12. Schoettle, B.; Sivak, M. A Survey of Public Opinion about Autonomous and Self-Driving Vehicles in the U.S., the U.K., and Australia; University of Michigan, Transportation Research Institute: Ann Arbor, MI, USA, 2014; pp. 1-38.

13. Krueger, R.; Rashidi, T.H.; Rose, J.M. Preferences for shared autonomous vehicles. Transp. Res. Part C Emerg. Technol. 2016, 69, 343-355. [CrossRef]

14. Howard, D.; Dai, D. Public Perceptions of Self-driving Cars: The case of Berkeley, California. In Proceedings of the Transportation Research Board 93rd Annual Meeting, Washington, DC, USA, 12-16 January 2014; pp. 226-243.

15. Hulse, L.M.; Xie, H.; Galea, E.R. Perceptions of autonomous vehicles: Relationships with road users, risk, gender and age. Saf. Sci. 2018, 102, 1-13. [CrossRef]

16. Kyriakidis, M.; Happee, R.; De Winter, J.C.F. Public opinion on automated driving: Results of an international questionnaire among 5000 respondents. Transp. Res. Part F Traffic Psychol. Behav. 2015, 32, 127-140. [CrossRef] 
17. Panagiotopoulos, I.; Dimitrakopoulos, G. An empirical investigation on consumers' intentions towards autonomous driving. Transp. Res. Part C Emerg. Technol. 2018, 95, 773-784. [CrossRef]

18. Rehrl, K.; Zankl, C. Digibus@: Results from the first self-driving shuttle trial on a public road in Austria. Eur. Transp. Res. Rev. 2018, 10, 51. [CrossRef]

19. Mahdavian, A.; Shojaei, A.; McCormick, S.; Papandreou, T.; Eluru, N.; Oloufa, A.A. Drivers and Barriers to Implementation of Connected, Automated, Shared, and Electric Vehicles: An Agenda for Future Research. IEEE Access 2021, 9, 22195-22213. [CrossRef]

20. Parasuraman, R.; Riley, V. Humans and Automation: Use, Misuse, Disuse, Abuse: Hum. Factors 2016, 39, 230-253. [CrossRef]

21. Bansal, P.; Kockelman, K.M.; Singh, A. Assessing public opinions of and interest in new vehicle technologies: An Austin perspective. Transp. Res. Part C Emerg. Technol. 2016, 67, 1-14. [CrossRef]

22. Bazilinskyy, P.; Kyriakidis, M.; de Winter, J. An International Crowdsourcing Study into People's Statements on Fully Automated Driving. Procedia Manuf. 2015, 3, 2534-2542. [CrossRef]

23. Moody, J.; Bailey, N.; Zhao, J. Public perceptions of autonomous vehicle safety: An international comparison. Saf. Sci. 2020, 121, 634-650. [CrossRef]

24. Nordhoff, S.; Kyriakidis, M.; van Arem, B.; Happee, R. A multi-level model on automated vehicle acceptance (MAVA): A review-based study. Theor. Issues Ergon. Sci. 2019, 20, 682-710. [CrossRef]

25. Eden, G.; Nanchen, B.; Ramseyer, R.; Evéquoz, F. Expectation and Experience: Passenger Acceptance of Autonomous Public Transportation Vehicles. Lect. Notes Comput. Sci. 2017, 10516 LNCS, 360-363. [CrossRef]

26. Ekman, F.; Johansson, M.; Bligård, L.O.; Karlsson, M.A.; Strömberg, H. Exploring automated vehicle driving styles as a source of trust information. Transp. Res. Part F Traffic Psychol. Behav. 2019, 65, 268-279. [CrossRef]

27. Madigan, R.; Louw, T.; Wilbrink, M.; Schieben, A.; Merat, N. What influences the decision to use automated public transport? Using UTAUT to understand public acceptance of automated road transport systems. Transp. Res. Part F Traffic Psychol. Behav. 2017, 50, 55-64. [CrossRef]

28. Portouli, E.; Karaseitanidis, G.; Lytrivis, P.; Amditis, A.; Raptis, O.; Karaberi, C. Public attitudes towards autonomous mini buses operating in real conditions in a Hellenic city. IEEE Intell. Veh. Symp. Proc. 2017, 4, 571-576. [CrossRef]

29. Benenson, R.; Fraichard, T.; Parent, M. Achievable safety of driverless ground vehicles. In Proceedings of the 10th International Conference on Control, Automation, Robotics and Vision, Hanoi, Vietnam, 17-20 December 2008; pp. 515-521.

30. Haeuslschmid, R.; Von Buelow, M.; Pfleging, B.; Butz, A. Supporting trust in autonomous driving. In Proceedings of the 22nd International Conference on Intelligent User Interfaces, Limassol, Cyprus, 13-16 March 2017; pp. 319-329. [CrossRef]

31. König, A.; Grippenkoven, J.D. Ridepooling, Mobility-on-demand, fahrerlose Busshuttles-Zur Psychologie des Teilens von Fahrten in bedarfsgesteuerten Mobilitätskonzepten. J. Mobil. Verk. 2019, 2, 10-22. [CrossRef]

32. Azad, M.; Hoseinzadeh, N.; Brakewood, C.; Cherry, C.R.; Han, L.D. Fully Autonomous Buses: A Literature Review and Future Research Directions. J. Adv. Transp. 2019, 2019, 4603548. [CrossRef]

33. Salonen, A.O. Passenger's subjective traffic safety, in-vehicle security and emergency management in the driverless shuttle bus in Finland. Transp. Policy 2018, 61, 106-110. [CrossRef]

34. Singh, P.; Dulebenets, M.A.; Pasha, J.; Gonzalez, E.D.R.S.; Lau, Y.; Kampmann, R. Deployment of Autonomous Trains in Rail Transportation: Current Trends and Existing Challenges. IEEE Access 2021, 9, 1. [CrossRef]

35. Liu, P.; Yang, R.; Xu, Z. How Safe Is Safe Enough for Self-Driving Vehicles? Risk Anal. 2019, 39, 315-325. [CrossRef]

36. Waycaster, G.C.; Matsumura, T.; Bilotkach, V.; Haftka, R.T.; Kim, N.H. Review of Regulatory Emphasis on Transportation Safety in the United States, 2002-2009: Public versus Private Modes. Risk Anal. 2018, 38, 1085-1101. [CrossRef] [PubMed]

37. Hewitt, C.; Amanatidis, T.; Politis, I.; Sarkar, A. Assessing public perception of self-driving cars: The autonomous vehicle acceptance model. Int. Conf. Intell. User Interfaces Proc. IUI 2019, F1476, 518-527. [CrossRef]

38. Liu, P.; Yang, R.; Xu, Z. Public Acceptance of Fully Automated Driving: Effects of Social Trust and Risk/Benefit Perceptions. Risk Anal. 2019, 39, 326-341. [CrossRef] [PubMed]

39. Cartenì, A. The acceptability value of autonomous vehicles: A quantitative analysis of the willingness to pay for shared autonomous vehicles (SAVs) mobility services. Transp. Res. Interdiscip. Perspect. 2020, 8, 100224. [CrossRef]

40. Bartneck, C.; Kanda, T.; Mubin, O.; Al Mahmud, A. Does the Design of a Robot Influence Its Animacy and Perceived Intelligence? Int. J. Soc. Robot. 2009, 1, 195-204. [CrossRef]

41. Lee, J.-G.; Kim, K.J.; Lee, S.; Shin, D.-H. Can Autonomous Vehicles Be Safe and Trustworthy? Effects of Appearance and Autonomy of Unmanned Driving Systems. Int. J. Hum. Comput. Interact. 2015, 31, 682-691. [CrossRef]

42. Choi, J.K.; Ji, Y.G. Investigating the Importance of Trust on Adopting an Autonomous Vehicle. Int. J. Hum. Comput. Interact. 2015, 31, 692-702. [CrossRef]

43. Koo, J.; Kwac, J.; Ju, W.; Steinert, M.; Leifer, L.; Nass, C. Why did my car just do that? Explaining semi-autonomous driving actions to improve driver understanding, trust, and performance. Int. J. Interact. Des. Manuf. 2014, 9, 269-275. [CrossRef]

44. Xu, Z.; Zhang, K.; Min, H.; Wang, Z.; Zhao, X.; Liu, P. What drives people to accept automated vehicles? Findings from a field experiment. Transp. Res. Part C Emerg. Technol. 2018, 95, 320-334. [CrossRef]

45. Nordhoff, S.; de Winter, J.; Payre, W.; van Arem, B.; Happee, R. What impressions do users have after a ride in an automated shuttle? An interview study. Transp. Res. Part F Traffic Psychol. Behav. 2019, 63, 252-269. [CrossRef] 
46. Kostorz, N.; Hilgert, T.; Kagerbauer, M. Automatisierte Kleinbusse im Öffentlichen Personennahverkehr-Akzeptanz und Nutzungsintentionen in Deutschland. J. Mobil. Verk. 2019, 2, 23-32. [CrossRef]

47. Paddeu, D.; Parkhurst, G.; Shergold, I. Passenger comfort and trust on first-time use of a shared autonomous shuttle vehicle. Transp. Res. Part C Emerg. Technol. 2020, 115, 102604. [CrossRef]

48. O'Cathain, A.; Thomas, K.J. "Any other comments?" Open questions on questionnaires-A bane or a bonus to research? BMC Med. Res. Methodol. 2004, 4, 25. [CrossRef] [PubMed]

49. Fink, A. How to Conduct Surveys: A Step-by-Step Guide; SAGE Publications: Thousand Oaks, CA, USA, 2006.

50. Agresti, A. An Introduction to Categorical Data Analysis; John Wiley \& Sons: Hoboken, NJ, USA, 2007.

51. Bakalos, N.; Papadakis, N.; Litke, A. Public Perception of Autonomous Mobility Using ML-Based Sentiment Analysis over Social Media Data. Logistics 2020, 4, 12. [CrossRef]

52. Ly, K.; Soman, D. Nudging Around The World; Rotman School of Management: Toronto, ON, Canada, 2013.

53. Eden, G.; Nanchen, B.; Ramseyer, R.; Eveìquoz, F. On the road with an autonomous passenger shuttle: Integration in public spaces. Conf. Hum. Factors Comput. Syst. Proc. 2017, F1276, 1569-1576. [CrossRef]

54. Hilgarter, K.; Granig, P. Public perception of autonomous vehicles: A qualitative study based on interviews after riding an autonomous shuttle. Transp. Res. Part F Traffic Psychol. Behav. 2020, 72, 226-243. [CrossRef]

55. Chee, P.N.E.; Susilo, Y.O.; Wong, Y.D.; Pernestål, A. Which factors affect willingness-to-pay for automated vehicle services? Evidence from public road deployment in Stockholm, Sweden. Eur. Transp. Res. Rev. 2020, 12, 20. [CrossRef]

56. Haghzare, S.; Campos, J.L.; Bak, K.; Mihailidis, A. Older adults' acceptance of fully automated vehicles: Effects of exposure, driving style, age, and driving conditions. Accid. Anal. Prev. 2021, 150, 105919. [CrossRef] [PubMed]

57. Wicki, M.; Guidon, S.; Becker, F.; Axhausen, K.; Bernauer, T. How technology commitment affects mode choice for a self-driving shuttle service. Res. Transp. Bus. Manag. 2019, 32, 100458. [CrossRef]

58. Liljamo, T.; Liimatainen, H.; Pöllänen, M. Attitudes and concerns on automated vehicles. Transp. Res. Part F Traffic Psychol. Behav. 2018, 59, 24-44. [CrossRef]

59. König, M.; Neumayr, L. Users' resistance towards radical innovations: The case of the self-driving car. Transp. Res. Part F Traffic Psychol. Behav. 2017, 44, 42-52. [CrossRef]

60. Niu, D.; Terken, J.; Eggen, B. Anthropomorphizing information to enhance trust in autonomous vehicles. Hum. Factors Ergon. Manuf. Serv. Ind. 2018, 28, 352-359. [CrossRef] 